\title{
A Jurisprudência Brasileira da Transexualidade: uma reflexão à luz de Dworkin ${ }^{1}$
}

\author{
Brazilian Transexuality Jurisprudence: an insight based on Dworkin
}

Maria Eugenia Bunchaft

Universidade do Vale do Rio dos Sinos, São Leopoldo - RS, Brasil

\begin{abstract}
Resumo: A transexualidade é um dos temas mais controversos da bioética. A temática é encoberta por autocompreensões assimétricas de mundo vinculadas a concepções religiosas, que terminam por minimizar os aspectos jurídicos fundamentais relativos ao direito à identidade sexual. Por meio da análise de diferentes projetos de lei, que tratam da temática da transexualidade, objetiva-se provar que a insuficiência da atuação do processo político majoritário na satisfação de demandas sociais específicas de transexuais tem sido suprida pelo papel pedagógico da atuação de alguns tribunais e do Superior Tribunal de Justiça na interpretação do direito de mudança do prenome e do sexo. Propugna-se investigar a relevância da estratégia de conciliação de valores em uma rede harmoniosa para a análise dos princípios jurídicos envolvidos na temática da mudança de prenome e de sexo por transexuais.
\end{abstract}

Palavras-chave: Transexualidade. Ativismo Judicial. Dworkin.

1 Recebido em: 06/08/2013

Revisado em: 14/11/2013

Aprovado em: 18/11/2013

\begin{abstract}
Transsexuality is one of the most controversial topics in bioethics. The issue is clouded by asymmetric self-judegements of the world linked to religious conceptions, which ultimately minimize the legal aspects related to the fundamental right to sexual identity. Through the analysis of different bills dealing with the issue of transsexuality we intend to demonstrate that the failure of the performance of majoritarian political process in satisfying social demands specific transsexuals have been supplied by the pedagogical role of the performance of some courts and the Superior Court of Justice on the interpretation of the right to change the given name and sex. Currently proposing to investigate the relevance of the strategy to reconcile values in a harmonious network for the analysis of the legal principles involved in the issue of change of first name, sex and transsexuals.
\end{abstract}

Keywords: Transexuality. Judicial Activism. Dworkin. 


\section{Introdução}

A transexualidade é um dos temas mais controversos da bioética. A temática é encoberta por autocompreensões assimétricas de mundo vinculadas a concepções religiosas, que terminam por minimizar os aspectos jurídicos fundamentais relativos ao direito à identidade sexual. A união entre homem e mulher, considerada um alicerce fundamental de uma sociedade construído em torno do núcleo familiar, aos poucos, passa a ser questionada. Inicialmente, a união entre homem e mulher era algo inquestionável, razão pela qual a moralidade majoritária inspirava discriminações contra os homossexuais. Nesse aspecto, as religiões ocidentais delinearam compreensões morais que concebiam o sexo em uma dimensão reprodutora, voltada para a preservação da família e da espécie humana.

De início, é premente lecionar que a identidade sexual vem sendo compreendida de forma mais ampla que o simples sexo morfológico. $\mathrm{O}$ sexo deixa de ser considerado como um elemento fisiológico, geneticamente determinado e imutável, contemplando os componentes genético, endócrino, morfológico, civil e psíquico. Ana Paula Ariston Barion Peres (2001) ainda acrescenta duas categorias: o sexo psicossocial e o sexo de criação. Elimar Szaniawsky (1998) destaca que o sexo psíquico contempla o sexo de criação, associado ao ambiente responsável pelo processo de desenvolvimento infantil. Em suma, decorre do relacionamento familiar e da educação transmitida à criança, tendo em vista o desenvolvimento do seu papel social feminino ou masculino.

Nessa linha de raciocínio, em regra, há uma compatibilidade entre sexo biológico, legal e de criação. Em determinadas situações, todavia, pode haver uma incompatibilidade entre a identidade de gênero e o sexo de criação, tendo em vista a concepção de sexo psicossocial. Segundo Antonio Chaves (2004, p, 128), o sexo psicossocial decorre de interações genéticas, fisiológicas e psicológicas que irão delimitar a estruturação do comportamento e da identidade sexual do indivíduo. O sexo psicossocial pressupõe uma articulação de diversos fatores, inspirando a identidade de gênero, que é a autocompreensão do indivíduo sobre sua sexualidade. No entanto, o sexo psicossocial pode ser incompatível com o sexo biológico: 
o indivíduo é biologicamente perfeito, mas identifica-se com o sexo feminino.

Nesse ponto, os tribunais têm partido de uma leitura moral do ordenamento jurídico e de uma perspectiva reconstrutiva, superando autocompreensões assimétricas de mundo. Por meio da análise de diferentes projetos de lei, que tratam da temática da transexualidade, pretende-se demonstrar que a insuficiência da atuação do processo político majoritário na satisfação de demandas sociais específicas de transexuais tem sido suprida pelo papel pedagógico da atuação de alguns tribunais e do Superior Tribunal de Justiça na interpretação do direito de mudança do prenome e do sexo. Mas por que motivo se faz imprescindível a compreensão da teoria do valor delineada por Dworkin na análise da temática dos direitos de transexuais na jurisprudência brasileira? É necessária, porque a temática da transexualidade não é apenas uma questão de política, mas, sobretudo, uma questão de princípio. A temática do transexualismo enseja, de um lado, um debate sobre a concepção de justiça, segurança jurídica, democracia, igualdade e liberdade na sua argumentação, que são conceitos interpretativos pertencentes ao domínio do valor.

De outro lado, recentes decisões judiciais do STJ na regulamentação do direito à mudança de prenome e sexo por transexuais inspiram uma possível discussão sobre monismo e pluralismo de valores. O pluralismo de valores é uma das questões mais discutidas na filosofia política contemporânea. Essa temática é analisada por Dworkin em Justice for Hedgehogs (2011), onde enfrenta a problemática da contraposição entre monismo e pluralismo de valores. O título da obra diz respeito ao poema de Arquíloco, a que se refere Isaiah Berlin em seu livro, The Hedgehogs and the Fox: An Essay on Tolstoy's View of History (1993), no qual discute a problemática do monismo e pluralismo. Portanto, "[...] a raposa sabe muitas coisas, mas o porco-espinho sabe apenas uma e grandiosa coisa [...]", afirma o poeta grego Arquíloco. (BERLIN, 1993, p. 435)

Não obstante toda a perspicácia da raposa e a possibilidade de desenvolver estratégias variadas para capturar o ouriço, no fim, a raposa termina superada pela mesma artimanha de sempre: o ouriço transforma-se em uma bola com espinhos apontando para direções diversas, inviabili- 
zando o seu bote. Para Berlin, essa célebre passagem de Arquíloco pode ser resgatada para classificar escritores e pensadores como ouriços e outros como raposas. Propugna-se investigar a relevância da estratégia de conciliação de valores em uma rede harmoniosa para a análise dos princípios jurídicos envolvidos na temática da mudança de prenome e sexo por transexuais. Adotando uma perspectiva eminentemente substancialista, Dworkin sustenta que a interpretação racionalmente construída a partir de princípios substantivos deve considerar, não apenas a Constituição como um todo, mas também a história, as tradições e as práticas constitucionais. Feitas essas considerações, realiza-se a análise da temática do transexualismo.

\section{Do Sexo e da Identidade Sexual}

Antes de tudo, é mister destacar que a transexualidade constitui uma desordem de identidade de gênero na qual a pessoa tem a convicção de pertencer ao sexo oposto e um desejo irreversível de adaptar o corpo físico à imagem que faz de si mesmo. A transexualidade pressupõe uma incompatibilidade entre o sexo biológico e a identidade psíquica. Desse modo, a cirurgia de transgenitalização objetiva compatibilizar o sexo morfológico e o sexo psicossocial. A primeira cirurgia de redesignação, que foi realizada no Brasil, ocorreu com o transexual Waldir Nogueira em 1971. Não obstante, o Ministério Público ofereceu denúncia contra o médico pela prática de crime de lesões corporais de natureza gravíssima, o que ensejou a sua condenação em primeira instância a dois anos de reclusão. Em $2^{\circ}$ grau foi absolvido, pois o tribunal compreendeu a inexistência de ação dolosa em sua atividade profissional, tendo caráter terapêutico.

Assim, durante alguns anos, o Conselho Federal de Medicina compreendia que essa cirurgia tinha caráter mutilante e não corretivo, de forma que o médico que a praticasse cometia crime de lesão corporal. A partir da Resolução n. 1.482/97, a cirurgia de mudança de sexo passou a ser considerada não criminosa. O Conselho Federal de Medicina editou, em 2002, a Resolução n. 1.652/02, que está em vigor até os dias atuais. No entanto, antes de realizar a cirurgia, o transexual deve se submeter a um 
acompanhamento por uma equipe médica multidisciplinar constituída por psiquiatra, cirurgião, endocrinologista, psicólogo e assistente social por período não inferior a dois anos. Somente podem ser operados os transexuais maiores de 21 anos.

Primeiramente, incumbiu-se a resolução de definir a síndrome transexual. Para ser transexual, o indivíduo deve ter profunda insatisfação com o sexo anatômico, desejo expresso de eliminar as genitais, permanência desse distúrbio de forma contínua e consistente por, no mínimo dois anos e ausência de outros transtornos mentais. Antes do advento do Novo Código Civil, a doutrina divergia sobre o caráter ilícito da cirurgia de transgenitalização. Autores contrários à licitude da cirurgia argumentavam que ela desconsiderava uma dimensão ética, ensejando danos irreparáveis ao corpo físico e saudável, sendo uma medida muito drástica que não conduzia ao equilíbrio psíquico e à tão sonhada adaptação social. Alegava-se também que o direito à liberdade sexual não suscitava o direito irrestrito sobre a própria corporeidade. A liberdade sexual não se confundiria com a liberdade de escolher o próprio sexo, que é inalterável.

O Novo Código Civil resolveu a questão controvertida relativa à licitude da cirurgia de transgenitalização, pois o artigo 13 dispõe que "Salvo exigência médica, é defeso ato de disposição do próprio corpo, quando importar em diminuição permanente da integridade física ou contrariar os bons costumes". A cirurgia de redesignação é permitida por lei, pois é realizada por exigência médica e possui caráter terapêutico. A problemática surge quando, depois de realizada a cirurgia, o pedido de modificação do prenome e do status sexual é indeferido e há uma incompatibilidade entre a aparência da pessoa e o seu sexo jurídico.

\section{Mudança do Prenome e do Status Sexual na Jurisprudência Brasileira}

Durante a década de 1980, a jurisprudência dos tribunais havia consagrado a tese da imutabilidade do prenome e do estado sexual no registro. Somente as retificações da Lei de Registros Públicos eram admitidas, pois o registro público deveria ser preciso e regular, constituindo 
expressão da verdade. Quanto à mudança de sexo, o entendimento era no sentido de que sexo não era uma questão de escolha, mas determinado biologicamente. Consequentemente, a cirurgia não suscitava uma verdadeira alteração do sexo. Tal retificação do registro civil só era admitida, em regra, no caso do intersexual.

Nesse sentido, a modificação em relação ao entendimento da matéria surge na década de 1990 na jurisprudência do Tribunal de Justiça do Rio Grande do Sul, que passou a decidir favoravelmente em relação à admissibilidade da modificação do registro do transexual redesignado. Com a Resolução n. 1.482/97 do Conselho Federal de Medicina, alguns tribunais brasileiros passaram a decidir pela licitude da cirurgia e pela admissibilidade da mudança do prenome. O entendimento passou a ser no sentido de que nada adiantará ao transexual a cirurgia, se houver a situação vexatória de se apresentar à sociedade com um prenome incompatível com a sua situação física.

É mister sublinhar que a regra da imutabilidade prevista no artigo 58 da Lei de Registros Públicos passou a ser relativizada pela jurisprudência no sentido de assegurar ao transexual operado o direito a um prenome sexo no registro que não o exponha a uma situação vexatória, havendo vários acórdãos dos Tribunais de Justiça de São Paulo, Rio de Janeiro, Rio Grande do Sul e Pernambuco que buscam adequar o prenome e o estado sexual do transexual.

Diante dessa estrutura conceitual, há um primeiro entendimento doutrinário que defende a admissibilidade de alteração do prenome, averbando-se o termo transexual no registro para garantir que outrem não seja induzido a erro. Mesmo entre os autores que consideram a admissibilidade alteração do status sexual, há controvérsia em relação à possibilidade de constar ressalva no registro sobre a condição de transexualidade. Maria Helena Diniz (2006, p. 300) leciona que, após a cirurgia da transgenitalização, o registro deve realizar a alteração sem a ressalva, sob pena de ofensa à dignidade humana.

Nesse particular, a autora destaca que a nova certidão de nascimento não deve contemplar qualquer observação quanto à natureza das retificações procedidas, consignando-se somente a ressalva de que o assento 
foi modificado por sentença judicial em ação de retificação do registro, cujo teor é segredo de justiça. A certidão com inteiro teor do mandado poderia ser fornecida a critério do juiz para salvaguarda de direitos. Nesse quadro teórico, defende-se, com base em Antonio Chaves (1994, p. 161), a impossibilidade de qualquer ressalva nos documentos, ainda que sigilosa, porque a lei veda qualquer discriminação.

Nessa configuração normativa, o artigo 196 da Constituição Federal prevê o direito à saúde, que contempla o direito ao equilíbrio físico mental do transexual e constitui a base jurídica para a adequação do sexo e prenome. O transexual deve ostentar um prenome pelo qual é conhecido, que espelha a verdade, pois o registro deve estar em consonância com a realidade.

Por outro lado, o direito à vida, à integridade psicofísica e à saúde constituem o trinômio que informa o livre desenvolvimento da personalidade e a salvaguarda da dignidade da pessoa humana. Esse princípio é determinante em qualquer questão de biodireito, estando previsto no artigo $1^{\circ}$, inciso III, da Carta Magna, como um valor fundamental sobre o qual se funda a República. $\mathrm{O}$ direito à busca do equilíbrio do corpo-mente está ancorado no direito à saúde e no direito à identidade sexual que integra um aspecto da identidade pessoal. O Tribunal de Justiça de São Paulo deferiu alteração de prenome e de sexo a transexual redesignado, conforme ementa transcrita:

Tribunal de Justiça de São Paulo. $1^{\text {a }}$ Câmara de Direito Privado. APL 9069885-07.2007.8.26.0000. Des. Relator Luiz Antonio de Godoy. D.J 10/01/2012.

[...] Ementa: REGISTRO CIVIL. Retificação. Transexual submetido à cirurgia de redesignação sexual. Alteração do prenome e designativo de exo. Possibilidade. Princípio da dignidade da pessoa humana. Alteração do registro civil, de modo a refletir a verdade real vivenciada pelo transexual e que se reflete na sociedade. Ação procedente. Retificação dos fundamentos da sentença. Recurso desprovido. (SÃO PAULO, 2012b) 
No entanto, a jurisprudência majoritária permite a alteração de prenome independentemente da realização da cirurgia de transgenitalização, mas negando quanto à alteração de gênero no registro, condicionando-o ao procedimento cirúrgico. Nesse sentido, manifestou-se o Tribunal de Justiça de Sergipe através da $1^{\mathrm{a}}$ Câmara Cível no julgamento da Apelação Cível n. 2012209865 por meio da relatora, Desembargadora Maria Aparecida Santos da Silva (Diário da Justiça 9/7/2012):

Tribunal de Justiça de Sergipe. $1^{a}$ Câmara Cível. Apel. Cível n. 2012209865. Desembargadora Relatora Maria Aparecida Santos da Silva. D.J. 9/7/2012.

Ementa: Apelação cível. Retificação de registro. Transexual não submetido à cirurgia de alteração de sexo. Modificação do prenome. Possibilidade. Autor submetido a situações vexatórias e constrangedoras todas as vezes em que necessita se apresentar com o nome constante em seu registro de nascimento. Princípio da dignidade da Pessoa Humana. Alteração do gênero biológico constante em seu registro de masculino para transexual sem ablação de sua genitália. Impossibilidade. (SERGIPE, 2012)

No mesmo raciocínio, exigindo a cirurgia para mudança do status sexual, manifestou-se o Tribunal de Justiça do Estado de Minas Gerais, através da Sexta Câmara Cível no julgamento da apelação n. 10232100002611-0/001, por meio da Desembargadora Sandra Fonseca (D.J. 28/09/2012). Não obstante, em 2012, o Tribunal de Justiça de

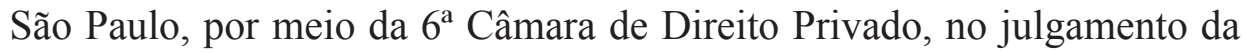
apelação n. 85395620048260505 SP 0008539-56.2004.8.26.0505, tendo como relator o Desembargador Vito Guglielmi (Diário da Justiça, de 18 de outubro de 2012), consignou ser dispensável a prévia cirurgia de transgenitalização para alteração do status sexual. A ementa do julgado estabelece os seguintes termos:

Tribunal de Justiça de São Paulo. $6^{\text {a }}$ Câmara de Direito Privado. Apel. n. 85395620048260505 SP 0008539-56.2004.8.26.0505. Desembargador Relator, Vito Guglielmi. D.J. 18/10/2012. 
Ementa Registro civil. Alteração de prenome e sexo da requerente em virtude de sua condição de transexual. Admissibilidade. Hipótese em que provada, pela perícia multidisciplinar, a desconformidade entre o sexo biológico e o sexo psicológico da requerente. Registro civil que deve, nos casos em que presente prova definitiva do transexualismo, dar prevalência ao sexo psicológico, uma vez que determinante do comportamento social do indivíduo. Aspecto secundário, ademais, da conformação biológica sexual que torna despicienda a prévia transgenitalização. Observação, contudo, quanto à forma das alterações que devem ser feitas mediante ato de averbação com menção à origem da retificação em sentença judicial. Ressalva que não só garante eventuais direitos de terceiros que mantiveram relacionamento com a requerente antes da mudança, mas também preserva a dignidade de autora, na medida em que os documentos usuais a isso não farão qualquer referência. Decisão de improcedência afastada. Recursos providos. (SÃO PAULO, 2012)

No mesmo sentido, a $4^{\mathrm{a}}$ Câmara de Direito Privado do Tribunal de Justiça de São Paulo, no julgamento da Apelação n. 000749104.2013.8.26.0196, por meio do relator Desembargador Maia da Cunha (Diário da Justiça, 13 /08/2013), decidiu que a exigência de da cirurgia de transgenitalização como condição para mudança do status sexual no registro, viola o principio constitucional da dignidade humana. O Desembargador Maia da Cunha foi acompanhado pelo Desembargador Fábio Quadros, reformando a sentença do juiz de primeira instância, sendo vencido o Desembargador Carlos Teixeira Leite. Sob esse prisma, é oportuno transcrever a ementa do julgado:

Tribunal de Justiça de São Paulo. $4^{\text {a }}$ Câmara de Direito Privado. Apelação n. 0007491-04.2013.8.26.0196, Desembargador Relator, Maia da Cunha. D.J. 13/8/2013.

[...] Retificação de registro civil. Transexualidade. Pretensão à modificação da designação de sexo e nome. Interesse de agir presente mesmo antes da realização da de redesignação de gênero. Obediência ao princípio da dignidade da pessoa humana de que trata o artigo $1^{\circ}$, III da Constituição federal. Definitividade do registro civil que recomenda a realização de estudo médico pericial e psi- 
cossocial, bem como a requisição das fichas de atendimento do acompanhamento realizado quando da preparação para a cirurgia de mudança de sexo. Recurso provido, com recomendação. (SÃO PAULO, 2013)

A jurisprudência majoritária desde 2009 admite a mudança de sexo no registro após a cirurgia. Mas antes de 2009, havia controvérsia na jurisprudência, havendo decisões que consideravam o sexo não como uma questão de escolha, mas biologicamente determinado. No entanto, tal posicionamento foi superado desde 2009, quando o STJ, no julgamento do RESP n. 1008398/SP (BRASIL, 2009c), a Terceira Turma do STJ, por unanimidade, deu-lhe provimento, deferindo a alteração de prenome e de sexo de transexual redesignado, tendo como relatora a Ministra Nancy Andrighi. Tal julgamento será oportunamente analisado. No momento, importa aprofundar a reflexão sobre a interpretação na teoria de Dworkin, que assume especial relevância para a temática da transexualidade.

\section{A Interpretação na Teoria de Dworkin}

A interpretação assume especial relevância para a teoria dworkiniana. Dworkin divide o processo interpretativo em três etapas. Na fase pré-interpretativa, há um elevado grau de convergência sobre a configuração dos elementos da prática objeto de interpretação, identificando-se “[...] as regras e padrões que consideram fornecer o conteúdo experimental da prática" (DWORKIN, 2003, p. 81). Na fase interpretativa, o intérprete estabelece uma "[...] justificativa geral para os principais elementos da prática identificada na etapa pré-interpretativa” (DWORKIN, 2003, p. 81), ou seja, inicia-se a fase de justificação. Por fim, na fase pós-interpretativa, o intérprete ajusta determinados argumentos substantivos aos princípios estabelecidos na etapa anterior. Nesse ponto,

[...] a justificativa não precisa ajustar-se a todos os aspectos ou características da prática estabelecida, mas deve ajustar-se o suficiente para que o intérprete possa ver-se como alguém que interpreta essa prática, não como alguém que inventa uma nova prática. (DWORKIN, 2003, p. 81) 
Em síntese, Dworkin (2003, p. 225-228) estabelece três virtudes políticas aceitas em um Estado Democrático que são padrões de legitimação do direito e das instituições políticas: equidade, justiça e devido processo legal. A equidade pressupõe que os procedimentos políticos sejam organizados de maneira que o poder seja distribuído em proporções equitativas, permitindo que os cidadãos tenham influência sobre as decisões públicas. A justiça, por sua vez, é uma virtude que analisa o resultado de uma decisão, tendo em vista a justificativa para a correta distribuição de bens, oportunidades e recursos. No ensejo, a virtude do devido processo legal diz respeito aos procedimentos adequados no julgamento dos cidadãos que violam a lei.

Nesse quadro teórico, são tratadas três virtudes políticas que são relevantes fundamentos de legitimação do direito e das instituições políticas em um Estado democrático. A integridade, por sua vez, é um ideal político que pressupõe que os governos devem tratar os cidadãos com igual consideração e respeito, protegendo-os contra a parcialidade e a fraude. Sob esse prisma, é clara a assertiva de Dworkin:

Mostrarei que uma sociedade política que aceita a integridade como virtude política se transforma, desse modo, em uma forma especial de comunidade, especial num sentido que promove sua autoridade moral para assumir e mobilizar o monopólio de força coercitiva. Este não é o único argumento em favor da integridade, ou a única conseqüência de reconhecê-la que poderia ser valorizada pelos cidadãos. A integridade protege contra a parcialidade, a fraude e outras formas de corrupção oficial, por exemplo. [...] (DWORKIN, 2003, p. 228)

Nessa perspectiva, o Estado deve agir de forma coerente e suas decisões devem ser fundamentadas com base na melhor interpretação do sistema jurídico e dos princípios públicos de justiça. Nas palavras de Dworkin,

[...] os juízes que aceitam o ideal interpretativo da integridade, decidem casos difíceis tentando encontrar em algum conjunto coerente de princípio sobre direitos e deveres das pessoas, a melhor 
interpretação da estrutura política e da doutrina jurídica de sua comunidade. (DWORKIN, 2003, p. 305)

Diante de uma multiplicidade de possibilidades interpretativas aceitáveis, o juiz indaga-se qual delas apresenta a estrutura das instituições e decisões da comunidade na sua melhor luz e do ponto de vista da moral política.

Assim como o romance em cadeia pressupõe um equilíbrio sutil entre diferentes tipos de atitudes artísticas e literárias, a interpretação no direito pressupõe um delicado equilíbrio entre convicções políticas diversas. Em Justice for Hedgehogs, Dworkin (2011) amplia o sentido do conceito de integridade, vinculando-o à ideia de responsabilidade, estabelecendo uma perspectiva moral mais ampla do que sustentada em $O$ Império do Direito (2003). A ideia de integridade agora está associada à ideia de concepção de dignidade humana. A ideia de que os indivíduos deveriam ser tratados com igual consideração e respeito uns com os outros em suas relações na comunidade, em Justice for Hedgehogs é resultante da concretização dos dois princípios de dignidade.

Sob esse aspecto, para Dworkin, o respeito pela dignidade humana implica em duas exigências: (1) o princípio do autorrespeito, segundo o qual "[...] cada pessoa deve levar a sua própria vida a sério; ela deve aceitar que é uma questão importante que sua vida seja uma realização de sucesso e não um desperdício de oportunidade" (DWORKIN, 2011, p. 203). O princípio do autorrespeito não é um princípio moral. Ele descreve uma atitude que o indivíduo deve ter em relação à sua própria vida, de forma que "[...] cada um de nós trate sua própria vida como tendo um tipo de importância”. (DWORKIN, 2003, p. 205)

Disso se infere que o princípio da autenticidade, por sua vez, pressupõe que

[...] cada pessoa tem uma responsabilidade especial e pessoal de identificar o que conta como sucesso em sua própria vida; ela tem uma responsabilidade pessoal de tornar a sua vida uma narrativa ou estilo coerente que ela própria endossa. (DWORKIN, 2003, p. 204) 
O que o princípio da autenticidade considera como crucial não é que se leve a vida diferentemente dos outros, mas em resposta à situação e aos valores considerados apropriados. De acordo com Dworkin, esses princípios desempenham um triplo papel: (1) fornecem um parâmetro sobre o que é preciso fazer para viver bem; (2) elucidam os direitos que os indivíduos possuem em face da comunidade política; (3) eles são a base para os deveres morais que se tem em relação aos outros.

Sob essa ótica, o autor destaca a existência de dois domínios inconfundíveis: o da ciência e do valor. A moralidade, a ética, o direito e a política pertencem ao mesmo domínio: o valor. Portanto, é imprescindível uma metodologia específica para a sua compreensão, que não se confunde com os métodos da investigação científica. Na esfera do valor, a metodologia apropriada é a interpretação, pois, por meio dela, articulam-se os diversos valores, eliminando a incerteza e a indeterminação no argumento moral. Alguns filósofos metaéticos afirmam que os juízos de valor não são "[...] descrições de uma realidade independente, mas sim expressões de preferências emocionais ou pessoais [...]" (DWORKIN, 2003, p. 201). Ou seja, as teorias filosóficas de segunda ordem não assumem posição sobre a moralidade do aborto, da discriminação contra transexuais, pois são descritivas e não substantivas e engajadas.

Desse modo, nas palavras de Dworkin (2010, p. 212), “[...] não se pode demonstrar que a análise filosófica dos conceitos políticos seja descritiva nos moldes da investigação científica das espécies naturais. A liberdade não tem DNA". E conclui:

Os conceitos de liberdade, democracia etc. funcionam como conceitos interpretativos de valor. O significado descritivo não pode ser removido da força valorativa porque o primeiro depende do segundo desse modo particular. (DWORKIN, 2010, p. 212)

Portanto, a análise de conceitos interpretativos não pode ser descritiva, neutra e desengajada, pois a estrutura dos valores políticos não é física, mas normativa. Valores políticos como justiça, democracia, dignidade humana não são autônomos nem conflitantes, devendo ser analisados de maneira integrada: 
Outrossim, no domínio do valor, é necessária uma metodologia diferenciada para responder questões normativas, pois inexistem morons no domínio do valor. Conceitos interpretativos como igualdade, liberdade, dignidade têm existência objetiva e sua justificação deve se dar por meio da interpretação conceitual. Portanto, o papel da filosofia política é delinear interpretações de cada um dos valores de forma que estes se reforcem mutuamente, como, por exemplo, uma concepção de democracia que seja útil à igualdade e à liberdade. Nas palavras de Dworkin $(2010, \mathrm{p}$. 228),

[...] além disso, seu objetivo deve ser elaborar essas concepções políticas como parte de uma estrutura de valor ainda mais inclusiva, que ligue a estrutura política não apenas à moral em termos gerais, mas também à ética.

Com efeito, o filósofo, em contraposição ao ceticismo, assume que o valor é objetivo e que a existência de respostas verdadeiras para as questões morais somente pode ser alcançada por meio da interpretação. Nas palavras de Dworkin (2010, p. 120),

[...] a fé do ouriço de que todos os verdadeiros valores formem uma rede entrelaçada, em que cada uma de nossas convicções sobre o que é bom ou certo ou belo possuem algum papel em sustentar cada uma de nossas outras convicções em cada um desses domínios de valor.

Nessa linha de raciocínio, Dworkin (2003; 2006; 2010; 1996; 2011), desde O Império do Direito (2003), assim como em Uma Questão de Princípio (2006), A Justiça de Toga (2010) e, por fim, em seu artigo, "Objective and Truth: you'd better believed it" (1996), delineou críticas ao ceticismo, encontrando um argumento definitivo e mais aprofundado em Justice for Hedgehogs (2011). Nesta obra, considera-se essa forma de ceticismo como aquele que nega qualquer base para si mesmo na moralidade e na ética, pressupondo uma inspeção externa, metaética, da verdade moral. $\mathrm{O}$ ceticismo externo arquimediano não acredita na possibilidade de se alcançar a verdade por meio de argumentos morais substantivos. 
A moralidade não é objetiva, pois inexistem critérios nas argumentações morais. A ideia é discutir a moralidade por meio de proposições fora da mesma. Inexistem partículas morais que capazes de sustentar os julgamentos de valores, razão pela qual não é possível afirmar a verdade na esfera moral.

Sob esse prisma, o ceticismo externo arquimediano nega a independência metafísica do valor. Essa forma de ceticismo estabelece uma distinção entre proposições substantivas de primeira ordem, que são julgamentos que as pessoas comuns emitem sobre liberdade, igualdade, democracia, justiça, legalidade e outros ideais políticos e as análises de segunda ordem, neutras e filosóficas, que são feitas pelos filósofos, sendo que estas são afirmações sobre a moralidade.

Nesse sentido, Dworkin (1996) contrapõe-se a tal perspectiva, porquanto nenhuma proposição de segunda-ordem pode refutar os argumentos de primeira-ordem. As proposições de segunda-ordem também se assentam em argumentos substantivos. Em seu artigo "Objective and Truth", Dworkin (1996) tece um dos mais relevantes comentários a respeito das proposições de primeira e segunda ordem:

Inicio dizendo que "O aborto é errado". Isso é, de acordo com o cético arquimediano, uma afirmação positiva de primeira ordem, uma proposição interna da moralidade. Agora, eu tomo fôlego e adiciono uma variedade de afirmações que os arquimedianos classificam como proposições externas, ao invés das do tipo interna. O que eu afirmei sobre o aborto não foi somente para desabafar minhas emoções ou descrever ou expressar minhas atitudes ou de outras pessoas. Minhas opiniões são verdadeiras [...]. Elas são, portanto, realmente objetivamente verdadeiras. Elas ainda seriam verdadeiras, isto é, mesmo que ninguém, a não ser eu, pensasse que seriam verdadeiras, ainda que eu mesmo não pensasse nelas como verdadeira. Elas são verdadeiras e absolutas [...]. (DWORKIN, 1996, p. 96-97)

Não obstante em obras anteriores, Dworkin (2003; 2006; 2010; 1996) já tenha estabelecido uma linha de argumentação contra o ceticismo externo arquimediano, o autor não havia encontrado um argumento definitivo até Justice for Hedgehogs. Nesta obra, Dworkin (2011) resgata 
o "princípio de Hume" com o objetivo de afirmar que o ceticismo arquimediano é autodestrutivo. O princípio de Hume, como axioma da metaética, determina que

[...] nenhuma série de proposições sobre como o mundo é, como uma questão de fato científico ou metafísico, pode fornecer um argumento de sucesso - sem algum julgamento de valor escondido em seus interstícios - para qualquer conclusão sobre o que deve ser aquele conjunto de proposições. (DWORKIN, 2011, p. 44)

\section{O Ouriço e a Unidade do Valor}

Dworkin assume-se como um autor vinculado ao grupo dos pensadores que adotam a perspectiva do ouriço. Segundo Berlin, para o grupo dos pensadores porcos-espinhos, tudo está conectado a uma visão central única, a um sistema mais ou menos coerente e articulado por meio de um princípio universal organizador. Para os pensadores que integram a perspectiva das raposas, a realidade compõe-se de uma multiplicidade de objetivos, frequentemente sem conexão e contraditórios. Sob esse prisma, é clara a assertiva de Berlin:

[...] de um lado, aqueles que relacionam tudo a uma única visão central, um sistema, mais ou menos coerente ou articulado, na forma em que compreendem, pensam e sentem - um único princípio universal organizador, nos termos de que sozinho tudo que são e dizem possui significado - e, no outro lado, aqueles que perseguem muitos objetivos, frequentemente não relacionados e mesmo contraditórios, e se forem conectados, são simplesmente em alguma maneira de facto, por alguma causa psicológica ou fisiológica, e não relacionado a nenhum princípio moral ou estético. [...] (BERLIN, 1993, p. 436)

Nessa trajetória teórica, Berlin (2002) enfrenta a questão do conflito entre monismo e pluralismo no artigo "Dois Conceitos de Liberdade", defendendo o pluralismo frente ao perigo do monismo moral. Para Berlin (2002, apud DWORKIN, 2010, p. 153-154), a ideia de unidade de valo- 
res, não apenas, é inatingível, mas também incoerente, porquanto “[...] o fato de garantir ou proteger um valor, implica, necessariamente, abandonar outros ou fazer concessões." A estratégia de conciliar valores em uma rede harmoniosa, para Berlin (2002, apud DWORKIN, 2010), poderia justificar práticas políticas totalitárias, demonstrando o perigo do ouriço. Mas, Dworkin (2010) defende uma antiga tese filosófica: a unidade do valor. A integridade, que antes vinculava-se somente ao direito e à política, agora conecta-se à moralidade e à ética às quais o Direito e a política devem se vincular.

Assim, Dworkin (2010) destaca a existência de perigo tanto no ponto de vista do ouriço, como no da raposa, pois "[...] o fato de o perigo do ouriço ser maior do que o da raposa, como pensava Berlin, parece depender, em grande parte, da questão de lugar e tempo" (DWORKIN, 2010, p. 152). Para o autor, se, na década de 1950 , o ouriço revelava-se mais ameaçador para a sociedade, nos Estados Unidos de hoje e nas democracias ocidentais, a civilização tem mais a temer a raposa. Em passagem elucidativa, sublinha que:

\begin{abstract}
É verdade que há perigos no ouriço, mas não devemos nos esquecer que também os há na raposa. Assim como os tiranos têm tentado justificar grandes crimes apelando à ideia de que todos os valores morais e políticos se unem em uma visão harmoniosa, de importância tão transcendental que o assassinato se justifica quando está a seu serviço, também outros crimes morais tem sido justificados por uma atração pela ideia oposta, a de que valores políticos importantes entram necessariamente em conflito, que não se pode defender escolha entre eles como a única escolha correta, e que sacrifícios em algumas das coisas que nos são caras são, portanto, inevitáveis. [...] (DWORKIN, 2010, p. 150-151)
\end{abstract}

Dworkin (2010) analisa o confronto entre liberdade e igualdade, porquanto se o governo estabelece impostos altos para minimizar as desigualdades econômicas, potencializando a igualdade, então a tributação não seria considerada uma violação da liberdade dos ricos. Sob essa ótica, “[...] a propriedade que lhes é tomada por meio de impostos não lhes pertence legitimamente" (DWORKIN, 2010, p. 160). Nesse sentido, é possí- 
vel mencionar, como exemplo de uma sensibilidade jurídica que concretiza a ideia de unidade de valor, a atuação do Superior Tribunal de Justiça na tutela de direitos de transexuais. Sob essa ótica, é fundamental refletir sobre a jurisprudência do STJ relativa a direitos de transexuais à luz da filosofia de Dworkin (2010).

\section{A Jurisprudência do STJ sobre Transexualidade: uma refle- xão à luz da perspectiva de Dworkin}

No deferimento do pedido de homologação da Sentença Estrangeira n. 001058, o STJ determinou a retificação do registro para atribuir sexo e prenome feminino a determinado transexual. $\mathrm{O}$ autor da ação ajuizou pedido de homologação de sentença estrangeira formulada pelo Tribunal de Gênova, na Itália, que estabeleceu a retificação do prenome e do sexo no registro civil após a realização de cirurgia para mudança de sexo. $\mathrm{O}$ Ministro-Presidente, Barros Monteiro, citou um acórdão paradigmático proferido pelo Tribunal de Justiça de São Paulo na apelação civil n 165.157-4/5, no qual o relator, Desembargador Boris Kaufmann, leciona que "[...] manter-se um ser amorfo, por um lado mulher, psíquica e anatomicamente reajustada, e por outro lado homem, juridicamente, em nada contribuiria para a preservação da ordem social e da moral [...]". Nesse sentido, é clara a assertiva do voto do Ministro Dr. Barros Monteiro:

Já na Declaração Universal dos Direitos de Homem, adotada e proclamada pela Resolução 217 A (III) da Assembléia Geral das Nações Unidas em 10 de dezembro de 1948, afirmava-se que a dignidade é inerente a todos os membros da família humana. E a Constituição em vigor inclui, entre os direitos individuais, a inviolabilidade da intimidade, da vida privada, da honra e da imagem das pessoas (art. $5^{\circ} \mathrm{X}$ ). Reside aqui o fundamento autorizador da mudança do sexo jurídico, pois, sem ela, ofendida estará a intimidade do autor, bem como sua honra. O constrangimento, a cada vez que se identifica, afastou o autor de atos absolutamente normais em qualquer indivíduo, pelo medo da chacota. A busca da felicidade, que é direito de qualquer ser humano, acabou comprometida. [...] (BRASIL, 2006) 
Em suma, o Ministro Barros Monteiro ponderou que a pretensão não ofende a soberania, a ordem pública ou os bons costumes, sendo fundamental conferir ao interessado

[...] uma identidade de gênero que lhe permita resolver a grave dicotomia em sua personalidade, com a possibilidade de garantir-lhe uma vida mais serena e de favorecer a sua integração social em sintonia com sua tendência natural. (BRASIL, 2006)

Verifica-se, por meio da leitura do voto do Ministro Barros Monteiro, como os princípios constitucionais foram utilizados pelo STJ, de forma a atribuir integridade moral ao ordenamento jurídico.

Indubitavelmente, as concepções de "ordem pública" e "bons costumes" representam conceitos jurídicos indeterminados que inspiram múltiplas possibilidades interpretativas. No caso específico, o STJ interpretou tais conceitos à luz dos princípios constitucionais da intimidade, da honra e da dignidade da pessoa humana. Percebe-se que, com base em tais princípios constitucionais de abertura argumentativa, o Tribunal foi capaz de desenvolver uma interpretação sofisticada do conceito de "ordem pública" capaz de resguardar uma esfera de independência ética inerente a cada indivíduo. A própria leitura moral da Constituição, a nosso ver, inspirou uma perspectiva reconstrutiva conectada à ideia de moral crítica, que rompe com autocompreensões assimétricas de mundo. Princípios constitucionais da intimidade, da honra e da dignidade da pessoa humana foram analisados de forma interdependente entre si, de forma a se unirem em uma rede harmoniosa. O STJ conseguiu justificar de forma coerente os conceitos que integram o domínio do valor, articulando-os de uma maneira que um complemente o sentido do outro, inexistindo conflito.

No processo de homologação da Sentença Estrangeira n . 002149 (BRASIL, 2006b), o mesmo relator, Ministro Barros Monteiro, também deferiu o processo de homologação com base nos mesmos argumentos (Diário da Justiça 11/12/2006). Nos processos relativos às Sentenças Estrangeiras n. 004179 (BRASIL, 2009a)e n. 002732 (BRASIL, 2009b), ambas julgadas em 7/04/2009, o relator, Ministro César Asfor Rocha, também deferiu o pedido de homologação, mas determinou que ficasse 
consignada, às margens do registro civil do requerente, a observação de que as modificações do nome e do sexo decorrem de decisão judicial. É de se mencionar, que, no julgamento do RESP n. 1008398/SP (BRASIL, 2009c), a Terceira Turma do STJ, por unanimidade, deu-lhe provimento em 15/10/2009, nos termos do voto da relatora, Ministra Nancy Andrighi, deferindo a alteração de prenome e de sexo de transexual redesignado, com base no princípio da dignidade da pessoa humana. A relatora, Ministra Nancy Andrighi, leciona que:

[...] conservar o sexo masculino no assento de nascimento do recorrente, em favor da realidade biológica e em detrimento das realidades psicológica e social, bem como morfológica, pois a aparência do transexual redesignado, em tudo se assemelha ao sexo feminino, equivaleria a manter o recorrente em estado de anomalia, deixando de reconhecer seu direito de viver dignamente. [...] (BRASIL, 2009c)

Dessa maneira, para compreender o significado dessa decisão à luz da teoria de Dworkin (2011), é necessário estabelecer a diferenciação do autor entre dois tipos de liberdade: freedom e liberty. A primeira configura a liberdade total e seu poder de agir para fazer o que quiser independentemente de restrições governamentais ou impostas por outros indivíduos; a segunda constitui a parte da liberdade-freedom que a comunidade política não pode restringir, sob pena de comprometer a sua dignidade (DWORKIN, 2011, p. 366). Dworkin estabelece três tipos de argumentos para justificar a liberdade. Em primeiro lugar, são necessárias algumas liberdades, especialmente a liberdade de expressão, porque são indispensáveis para um sistema justo e democrático de governo.

Em segundo lugar, tem-se o direito ao que se denomina de independência ética, ou seja, o direito de serem feitas escolhas fundamentais sobre o significado e importância da vida humana para nós mesmos. Por fim, novamente com base na independência ética, tem-se o direito de não ser negados qualquer liberdade quando a justificativa do governo repousa na popularidade ou de uma suposta superioridade de alguma concepção sobre a melhor maneira de viver. Portanto, o estabelecimento da imutabilidade do sexo de transexual redesignado no registro civil implicaria, 
como assinalou a ministra e relatora, a negação do seu direito a uma vida digna. O que, a nosso ver, violaria a sua independência ética.

\section{O Direito à Identidade Sexual à Luz do Substancialismo de Ronald Dworkin}

De início, é mister esclarecer que as obras de Dworkin (2002; 2003b; 2005) configuram-se como empreendimentos teóricos mais controversos da filosofia político-jurídica. Adotando uma perspectiva eminentemente substancialista, Dworkin (2006, p. 122-134) sustenta que a interpretação racionalmente construída a partir de princípios substantivos deve considerar, não apenas a Constituição, mas também a história, as tradições e as práticas constitucionais. É de se mencionar, ainda, a existência de uma divergência entre constitucionalistas americanos em relação aos denominados direitos expressos e implícitos (numerated and unumerated rights), ensejando o embate teórico entre perspectivas originalistas e não originalistas. Os primeiros pretendiam resgatar a intenção original dos Framers, considerando inadmissível uma postura construtiva que incorpore direitos não positivados no texto constitucional. Os originalistas afirmam que "[...] os juízes não têm autoridade para acrescentar novos direitos não enumerados [...]" uma vez que "[...] se deixarmos os juízes vagarem à vontade para além das quatro paredes da Constituição, teremos renunciado a toda esperança de limitar o poder do judiciário". (DWORKIN, 2006, p. 123)

Sob esse prisma, os não originalistas, por sua vez, pressupunham a realização pelo Judiciário dos direitos implícitos decorrentes de uma interpretação sistemática do texto constitucional. Contra os originalistas, Dworkin (2005, p. 235-249) formula a concepção de um direito em cadeia, segundo a qual os juízes, ao longo da história, constroem conjuntamente um complexo empreendimento em cadeia no qual cada ato de interpretação representa um capítulo que integra um grande romance redigido por diferentes escritores em distintos momentos. Nas palavras do autor, “[...] cada juiz, então, é como um romancista em corrente. Ele deve ler tudo o que outros juízes escreveram no passado, não apenas para des- 
cobrir o que disseram, ou seu estado de espírito quando o disseram [...]", mas para alcançar uma opinião sobre "[...] o que esses juízes fizeram coletivamente da maneira como cada um dos romancistas formou uma opinião sobre o romance coletivo escrito até então" (DWORKIN, 2005, p. 238). A partir da distinção entre regras e princípios, Dworkin (2002, p. 23-50) pressupõe certa margem de liberdade interpretativa na realização de uma moralidade ínsita ao texto constitucional, tendo em vista o reconhecimento de direitos implícitos.

Nesse contexto, a contraposição entre originalistas e não originalistas é superada em favor de uma perspectiva que concebe o direito em uma dimensão de integridade (DWORKIN, 2005, p. 43-58). Em síntese, o direito como integridade nega uma concepção do fenômeno jurídico como reflexo de práticas convencionais que são voltadas para o passado, ou filosofias pragmatistas voltadas para o futuro. Seria necessário articular ambos os elementos, interpretando a moralidade institucional de uma comunidade como um grande romance em cadeia. O direito como integridade rejeita a problemática da existência ou não de discricionariedade judicial, superando a contraposição entre interpretativistas e não interpretativistas com base na própria leitura moral da Constituição. Há uma ampliação das possibilidades de atuação do poder judicial sem que tal perspectiva implique usurpação das funções legislativas. Em suma, a própria abertura do texto constitucional traz novos horizontes interpretativos com base em princípios eleitos pelo povo. (DWORKIN, 2005, p. 217-249)

Nesse ponto, pondera o jurista pela inexistência de incompatibilidade entre democracia e direitos fundamentais, razão por que busca conciliar ambos os aspectos através de uma concepção substancialista de democracia constitucional. Propõe o jurista que, a despeito de uma multiplicidade de concepções de vida digna, os cidadãos compartilham uma concepção de justiça decorrente do fato de que todos os cidadãos devem ser tratados com igual respeito (DWORKIN, 2002, p. 419). Sua perspectiva está atenta à preservação da inviolabilidade da esfera de autonomia moral de cada indivíduo, de forma que nenhuma decisão política dos órgãos deliberativos poderá afetar esta esfera individual moralmente independente. $\mathrm{O}$ controle de constitucionalidade assume especial relevância, 
pois se torna um instrumento poderoso de preservação de direitos fundamentais em face de maiorias parlamentares.

Nessa linha de raciocínio, tal compreensão expressa uma perspectiva eminentemente liberal, visando a proteger uma esfera de liberdades individuais, cujo âmbito de atuação não pode ser restringido pelo processo político majoritário. Nessa perspectiva, compreendo, com base no autor, que o Judiciário pode assumir um papel fundamental na proteção de uma esfera de autonomia, sempre que a deliberação não for sensível a pretensões normativas de minorias e quando maiorias parlamentares imponham concepções abrangentes de bem que frustram o debate público.

Nesse cenário, Dworkin (2005, p. 95-103) parte do pressuposto segundo o qual as decisões políticas majoritárias nem sempre alcançam plenamente todas as concepções éticas individuais, razão por que há de se resguardar um complexo de direitos fundamentais frente ao poder de decisão das maiorias, com fundamento no princípio da autonomia moral. É nessa perspectiva que Dworkin (2005, p. 95-103) formula a concepção de comunidade de princípios, segundo a qual os indivíduos que formam um corpo social aceitam que suas vidas estejam ligadas por princípios comuns - criados através de um pacto político - que não podem ser restringidos pelas maiorias parlamentares.

Em síntese, a abordagem substantivista de Dworkin (2003b) foi alvo incessante de críticas, porquanto é acusada de fundamentar-se em uma perspectiva antidemocrática que concede aos juízes uma licença para impor suas convicções morais aos cidadãos. O constitucionalista contra-argumenta no sentido de que a legitimidade interpretativa dos juízes não é elitista e antidemocrática, na medida em que a leitura moral da Constituição é indispensável à democracia. Dworkin (2005, p. 80-103) defende um modelo de democracia constitucional relacionada a uma concepção que limita a esfera de atuação do governo em face das condições de associação moral, legitimando a leitura moral da Constituição a partir do ideal democrático. Para o jurista norte-americano, portanto, a leitura moral da Constituição, como método de interpretação, não implica discricionariedade judicial, pois o texto constitucional é permeado por uma moralidade 
política que deve ser alcançada através de uma perspectiva reconstrutiva, com fundamento no princípio da integridade.

Nesse quadro teórico, Dworkin (2005, p. 80-103) concilia o princípio da democracia com o judicial review, demonstrando que os valores políticos e morais consagrados pelo povo no ideário constitucional apenas podem ser alcançados através de uma leitura moral da Constituição. Do mesmo modo, não há porque defender uma soberania absoluta do poder legislativo, pois o princípio da igual consideração e respeito torna-se mais efetivo em uma democracia constitucional fundamentada no controle judicial dos direitos fundamentais. Postula um modelo de democracia constitucional desvinculada do princípio majoritário, porquanto somente a tutela judicial de tais direitos é capaz de consagrar a plenitude do potencial democrático.

Quando se concebe a arena constitucional como um cenário de lutas pelo reconhecimento, percebe-se que o Judiciário - como instância de representação de minorias - pode inspirar uma nova narrativa simbólica, um novo processo de articulação da diferença em uma cultura jurídico-constitucional aberta e inclusiva, sempre que as instâncias deliberativas mostrarem-se insensíveis às aspirações normativas de grupos estigmatizados.

No caso específico do transexualismo, alguns projetos de lei que tentavam regulamentar a matéria não foram aprovados e aqueles que atualmente tramitam no Congresso Nacional encontram óbices à sua aprovação. Nesse aspecto, é necessário analisar determinados os atuais projetos de lei que tratam da temática.

\section{Projetos de Lei sobre Transexualidade}

Atualmente, tramitam no Congresso Nacional diversos projetos de lei que tratam dos direitos dos transexuais, como, por exemplo, os Projetos de Lei n. 2.976/2008 (DIOGO, 2008), n. 1.281/2011 (LIMA, 2011), n. 658/2011 (RODRIGUES, 2011) e n. 4.241/2012. (KOKAY, 2012) 
Existe o Projeto de Lei da Câmara n. 72/2007 (ZICA, 2007), alterando o artigo 58 da Lei n. 6.015/73, que dispõe sobre registros públicos, possibilitando a alteração do prenome de pessoas transexuais:

Art. 58. O prenome será definitivo, admitindo-se, todavia, a sua substituição, mediante sentença judicial, nos casos em que:

I-o interessado for:

a)conhecido por apelidos notórios;

b) reconhecido como transexual de acordo com laudo de avaliação médica, ainda que não tenha sido submetido a procedimento médico-cirúrgico destinado à adequação dos órgãos sexuais;

II-houver fundada coação ou ameaça decorrente da colaboração com a apuração de crime por determinação, em sentença, de juiz competente após ouvido o Ministério Público.

Parágrafo único. A sentença relativa à substituição do prenome na hipótese prevista na alínea $\mathrm{b}$ do inciso I deste artigo será objeto de averbação no livro de nascimento com a menção imperativa de ser a pessoa transexual.

Nessa perspectiva, a Lei n. 6.015/73 estatui que toda alteração de prenome seja realizada pela via judicial, o projeto estabelece um procedimento simplificado e célere, prevendo a exigência de um laudo médico que comprove a condição da pessoa transexual. Em síntese, durante a discussão do projeto, surgiram inúmeras críticas dirigidas contra a necessidade de se averbar o nome no registro e a ausência de previsão específica para alteração de sexo. A novidade do projeto reside na possibilidade de o transexual requerer a adequação do prenome mesmo que não tenha se submetido à cirurgia de transgenitalização. O projeto encontra-se na Comissão de Constituição e Justiça do Senado, tendo sido distribuído ao Senador Eduardo Suplicy para emitir parecer.

A principal proposta legislativa é o Projeto de Lei n. 5.002/2013 (WYLLYS; KOKAY, 2013), que tramita na Câmara dos Deputados, estabelecendo o direito à identidade de gênero, concebida como a vivência interna e individual do gênero tal como cada pessoa o sente, a qual pode corresponder ou não com o sexo atribuído após o nascimento, incluindo 
a vivência pessoal do corpo (art. $2^{\circ}$ ). Segundo esse projeto, o SUS e os planos de saúde estariam obrigados a custear tratamentos hormonais integrais e cirurgias de transgenitalização a todos os interessados maiores de 18 anos. Estes últimos não estariam obrigados a satisfazer qualquer requisito relativo a um tipo de diagnóstico, tratamento ou autorização judicial. Além disso, o projeto prevê que os maiores de 18 anos podem mudar o prenome independentemente de autorização judicial. E libera também para eles a mudança do status sexual nos documentos pessoais com ou sem cirurgia.

Permite a manutenção dos números dos documentos, omitindo-se os nomes originais. Nas hipóteses de tratamento hormonal, cirurgia de transgenitalização e mudança de nome e sexo nos documentos, se o interessado for menor de 18 anos, é necessário requerimento dos pais ou representantes legais. Se eles se opuserem, o adolescente pode recorrer à defensoria pública para requerer a autorização judicial mediante procedimento sumaríssimo. O texto está pronto para votação em plenário. Enquanto tais propostas legislativas não são aprovadas, o Judiciário supre a lacuna legal. Sob esse aspecto, quando os mecanismos das instâncias deliberativas funcionam adequadamente, de forma a contemplar minorias estigmatizadas, a intervenção judicial minimiza-se; mas, quando a atuação dos órgãos políticos não atende às expectativas normativas de minorias insulares, a tendência é a atuação judicial expandir-se, de forma a suprir o déficit de abertura e participação das mesmas.

\section{Conclusão}

Diante do exposto, depreende-se que a insuficiência da atuação das instâncias deliberativas no provimento de demandas sociais específicas de transexuais tem sido suprida pelo papel pedagógico da atuação de alguns tribunais e do Superior Tribunal de Justiça na interpretação constitucional da questão da transexualidade, postura esta que se insere em um contexto mais amplo, revelando uma sensibilidade jurídica dos Tribunais Superiores em relação ao tema dos grupos estigmatizados, seja no que se refere aos direitos de transexuais, de homossexuais ou de índios. Com efeito, 
o instrumental teórico de Dworkin é relevante para analisar a temática da transexualidade na jurisprudência do STJ, pois o autor introduz uma concepção de democracia constitucional cujo pressuposto é a tutela judicial dos direitos fundamentais dos cidadãos, uma vez que eles devem ser tratados com igual consideração e respeito. Enquanto a democracia majoritária visa a tornar efetiva a vontade política da maioria, a sua concepção de democracia constitucional não se fundamenta na primazia das decisões políticas majoritárias, porquanto exige do governo o respeito a determinados princípios e direitos fundamentais cuja tutela será conduzida de melhor forma por meio do controle judicial.

Em situações estratégicas, portanto, a arena jurídica pode inspirar uma sensibilidade normativa para grupos minoritários, sobretudo em momentos nos quais o processo político majoritário não seja capaz de atender às pretensões de minorias estigmatizadas. Princípios como justiça, liberdade, igualdade, privacidade e segurança jurídica, que têm sido resgatados pelos tribunais na análise de casos envolvendo a transexualidade, funcionam como conceitos interpretativos pertencentes à esfera do valor, razão pela qual a sua análise não pode ser descritiva, neutra e desengajada, porquanto a sua estrutura normativa. Tais princípios de abertura argumentativa não devem ser interpretados de forma autônoma, mas de forma integrada.

Na temática dos direitos fundamentais de transexuais, diversos projetos de lei tentavam regulamentar a matéria e foram arquivados. Porém, compreende-se que o Judiciário pode suscitar narrativas simbólicas emancipatórias que inspiram a integração da diferença em uma cultura jurídica inclusiva sempre que as instâncias deliberativas mostrarem-se insensíveis às aspirações normativas de grupos estigmatizados. 


\section{Referências}

BERLIN, Isaiah. Dois Conceitos de Liberdade. In: BERLIN, Isaiah. Estudos sobre a humanidade: uma antologia de ensaios. São Paulo: Companhia das Letras, 2002.

BERLIN, Isaiah. The Hedgehogs and the Fox: an essay on Tolstoy's View of History. New York: Simon \& Schuster, 1993.

BRASIL. Lei n. 6.015, de 31 de dezembro de 1973. Dispõe sobre registros públicos e dá outras providências. Disponível em: $<$ http://www. planalto.gov.br/ccivil_03/leis/16015.htm>. Acesso em: 4 out. 2009.

BRASIL. Lei 10.406, de 10 de janeiro de 2002. Institui o Código Civil. Disponível em: < http://www.planalto.gov.br/ccivil_03/leis/2002/110406. htm>. Acesso em: 4 out. 2009.

BRASIL. Superior Tribunal de Justiça. Presidência. Sentença Estrangeira n. 001058. Voto do relator, Ministro Barros Monteiro. Brasília, DF, Diário da Justiça, de 4 de dezembro de 2006a. Disponível em: <www.stj.gov.br>. Acesso em: 4 out. 2009.

BRASIL. Superior Tribunal de Justiça. Presidência. Sentença Estrangeira n. 002149. Voto do relator, Ministro Barros Monteiro. Brasília, DF, Diário da Justiça, de $1^{\circ}$ de agosto de 2006b. Disponível em: $<$ www.stj.gov.br>. Acesso em: 4 out. 2009.

BRASIL. Superior Tribunal de Justiça. Presidência. Sentença Estrangeira n. 004179. Voto do relator, Ministro César Asfor Rocha. Brasília-DF, Diário da Justiça, de 7 de abril de 2009a. Disponível em: <www.stj.gov.br>. Acesso em: 4 out. 2009.

BRASIL. Superior Tribunal de Justiça. Presidência. Sentença Estrangeira n. 002732 . Voto do relator, Ministro César Asfor Rocha. Brasília, DF, Diário da Justiça, de 7 de abril de 2009b. Disponível em: <www.stj.gov.br>. Acesso em: 4 out. 2009. 
BRASIL, Superior Tribunal de Justiça. Terceira turma. Recurso Especial n. 1008398/SP. Voto da relatora, Ministra Nancy Andrighi. Brasília, DF, Diário da Justiça, de 15 de outubro de 2009c. Disponível em: <www.stj. gov.br>. Acesso em: 4 out. 2010.

CHAVES, Antonio. Direito à vida e ao próprio corpo: intersexualidade, transexualidade, transplantes. São Paulo: Revista dos Tribunais, 2004.

CONSELHO FEDERAL DE MEDICINA. Resolução n. 1.482, de 19 de setembro de 1997. Autoriza a título experimental a realização de cirurgia de transgenitalização. Disponível em: <http://www.portalmedico.org.br/ php/pesquisa_resolucoes.php $>$. Acesso em: 4 out. 2013.

CONSELHO FEDERAL DE MEDICINA. Resolução n. 1.652, de 2 de dezembro de 2002. Dispõe sobre a cirurgia de transgenitalismo e revoga a Resolução n. 1.482/97. Disponível em: <http://www.portalmedico.org. br/php/pesquisa_resolucoes.php>. Acesso em: 4 out. 2013.

CONSELHO FEDERAL DE MEDICINA. Resolução n. 1.955, de 3 de setembro de 2010. Dispõe sobre a cirurgia de transgenitalismo e revoga a Resolução n. 1.652/2002. Disponível em: <http://www.portalmedico. org.br/php/pesquisa_resolucoes.php>. Acesso em: 4 out. 2013.

DINIZ, Maria Helena. O Estado atual do biodireito. São Paulo: Saraiva, 2006.

DIOGO, Cida. Projeto de Lei n. 2.976/2008. Acrescenta o artigo 58-A ao texto da Lei n. 6.015, de 31 de dezembro de 1973, que dispõe sobre registros públicos. Disponível em: <http://www.camara.gov.br/ proposicoesWeb/fichadetramitacao?idProposicao=386164>. Acesso em: 13 out. 2013.

DWORKIN, Ronald. Objective and Truth: you'd better believed it. Philosophy and Public Affairs, Princeton, v. 25, n. 2, Princeton University Press, 1996.

DWORKIN, Ronald. Levando os direitos a sério. São Paulo: Martins Fontes, 2002.

DWORKIN, Ronald. Domínio da vida: aborto, eutanásia e liberdades individuais. São Paulo: Martins Fontes, 2003a. 
DWORKIN, Ronald. Império do direito. São Paulo: Martins Fontes, $2003 b$.

DWORKIN, Ronald. Uma questão de princípio. São Paulo: Martins Fontes, 2005.

DWORKIN, Ronald. Is Democracy Possible Here? Principles for a New Political Debate. Princeton: Princeton University Press, 2006. DWORKIN, Ronald. A Justiça de toga. São Paulo: Martins Fontes, 2010. p. 212.

DWORKIN, Ronald. Justice for Hedgehogs. Cambridge, Massachusetts: Belknap Press of Harvard University, 2011.

KOKAY, Erica. Projeto de Lei da Câmara n. 4.241/2012. Dispõe sobre o direito à identidade de gênero. Disponível em: $<$ http://www.camara. gov.br/proposicoesWeb/fichadetramitacao?idProposicao=552237>. Acesso em: 13 out. 2013.

LIMA, João Paulo. Projeto de Lei da Câmara n. 1.281/2011. Dispõe sobre a mudança de prenome da pessoa transexual que realizar cirurgia para troca de sexo. Disponível em: < http://www.camara.gov.br/ proposicoesWeb/fichadetramitacao?idProposicao=501425>. Acesso em: 13 out. 2013.

MINAS GERAIS. Tribunal de Justiça do Estado de Minas Gerais. Sexta Câmara Cível. Apelação cível n. 10232100002611-0/001. Voto da relatora, Desembargadora Sandra Fonseca. Diário da Justiça, Brasília, DF, de 28 de setembro de 2012. Disponível em: <www.tj.mg.gov.br>. Acesso em: 4 abr. 2013.

PERES, Ana Paula Ariston Barion. Transexualismo: o direito a uma nova identidade. Rio de Janeiro: Renovar, 2001.

RODRIGUES, Romero. Projeto de Lei do Senado n. 658/2011. Reconhece os direitos à identidade de gênero e à troca de nome e sexo nos documentos de identidade de transexuais. Disponível em: $<$ http://www.senado.gov.br/atividade/materia/detalhes.asp?p_cod_ mate $=103053>$. Acesso em: 13 out. 2013. 
SÃO PAULO. Tribunal de Justiça do Estado de São Paulo. Primeira Câmara de Direito Privado. Apelação n. 9069885-07.2007.8.26.0000. Voto do relator, Desembargador Luiz Antonio de Godoy. Diário da Justiça, Brasília, DF, de 10 de janeiro de 2012. Disponível em: <www. tj.sp.gov.br>. Acesso em: 4 abr. 2013.

SÃO PAULO. Tribunal de Justiça do Estado de São Paulo. Sexta Câmara de Direito Privado. Apelação n. 85395620048260505- SP 000853956.2004.8.26.0505. Voto do relator, Desembargador Vito Guglielmi. Diário da Justiça, Brasília, DF, de 18 de outubro de 2012. Disponível em: $<$ www.tj.sp.gov.br>. Acesso em: 4 abr. 2013.

SÃO PAULO. Tribunal de Justiça do Estado de São Paulo. Quarta Câmara de Direito Privado. Apelação n. 0007491-04.2013.8.26.0196. Voto do relator, Desembargador Maia da Cunha. Diário da Justiça, Brasília, DF, de 13 de agosto de 2013. Disponível em: <www.tj.sp.gov. br>. Acesso em: 4 abr. 2013.

SERGIPE. Tribunal de Justiça do Estado de Sergipe. Primeira Câmara Cível. Apelação cível n. 2012209865. Voto da relatora, Desembargadora Maria Aparecida Santos da Silva. Diário da Justiça, Brasília, DF, de 9 de julho de 2012. Disponível em: <www.tj.se.gov.br>. Acesso em: 4 abr. 2013.

\section{SZANIAWSKI, Elimar. Limites e possibilidades do direito de} redesignação sexual. São Paulo: Editora Revista dos Tribunais, 1998. WYLLYS, Jean; KOKAY, Erica. Projeto de Lei n. 5.002/2013. Dispõe sobre o direito à identidade de gênero e altera o artigo 58 da Lei n. 6.015, de 31 de dezembro de 1973. Disponível em: <http:/www.camara.gov.br/ proposicoesWeb/fichadetramitacao?idProposicao $=565315>$. Acesso em: 4 abr. 2013.

ZICA, Luciano. Projeto de Lei da Câmara n. 72/2007. Altera o artigo 58 da Lei n. 6.015/1973, que dispõe sobre registros públicos e dá outras providências, possibilitando a substituição do prenome de pessoas transexuais. Disponível em: <http://www.senado.gov.br/atividade/ materia/detalhes.asp?p_cod_mate=82449>. Acesso em: 4 abr. 2013. 
Maria Eugenia Bunchaft é Doutora e Mestre em Teoria do Estado e Direito Constitucional pela PUC-Rio. Professora do Programa de Pós-graduação em Direito da UNISINOS. Pós-Doutora em Filosofia pela UFSC. E-mail: mbunchaft@ig.com.br.

Endereço profissional: Av. Unisinos, 950, Cristo Rei. São Leopoldo, RS. CEP: 93022-000. 